\title{
Adoptive Transfer of Lymphocytes Sensitized to the Major Surface Glycoprotein of Pneumocystis carinii Confers Protection in the Rat
}

\author{
Sue A. Theus, ${ }^{\star}$ Ryan P. Andrews, * Paul Steele, ${ }^{\star}$ and Peter D. Walzer* \\ Cincinnati Veterans Affairs Medical Center and Division of Infectious Diseases, *Department of Internal Medicine, \\ ${ }^{\ddagger}$ Department of Pathology, University of Cincinnati College of Medicine, Cincinnati, Ohio 45220
}

\begin{abstract}
Pneumocystis carinii is a major opportunistic pathogen and a leading cause of morbidity in patients with AIDS. CD4 ${ }^{+}$ cells have been shown to be important in host defenses against $P$. carinii, but the antigen (s) involved with this response have not been identified. We undertook the present study to determine whether the major surface glycoprotein (MSG) of $P$. carinii contains epitopes that can elicit a protective cellular immune response. Spleen cells and purified $\mathrm{CD4}^{+}$cells isolated from Lewis rats, pulsed 1-4 d with MSG, and injected into corticosteroid-treated Lewis rats with pneumocystosis resulted in significant reduction in the $P$. carinii burden, as judged by organism quantitation and lung histology. The protective response demonstrated by the donor cells was dependent on previous exposure to $P$. carinii, cell concentration, and time of incubation with MSG. In addition, reconstitution with MSG-specific $\mathrm{CD4}^{+}$cells resulted in an early hyperinflammatory response within the lungs of these animals with a high percentage of mortality. Thus, in this model, MSG can elicit an immune response mediated by $\mathrm{CD4}^{+}$cells, which has a harmful as well as helpful effect on the host, and these responses occur despite the presence of corticosteroids. (J. Clin. Invest. 1995. 95:2587-2593.) Key words: AIDS • immunity • T cells • pneumonia $\cdot$ opportunistic infection
\end{abstract}

\section{Introduction}

Pneumocystis carinii is a major opportunistic pathogen and a leading cause of morbidity in patients with AIDS. Impaired cell-mediated immunity is considered to be the major host predisposing factor for $P$. carinii pneumonia (1). Major underlying conditions in $P$. carinii patients include AIDS, malignancies, protein malnutrition, and immunosuppressive drugs (particularly corticosteroids). In AIDS patients, the risk of developing $P$. carinii pneumonia rises with the progressive decline in the number and function of $\mathrm{CD}^{+} \mathrm{T}$ cells (2). In previous animal studies, Furuta ( 3 ) found that the transfer of $\mathrm{T}$ cells to $P$. cari-

Address correspondence to Peter D. Walzer, Associate Chief of Staff, Research Service, Veterans Affairs Medical Center, 3200 Vine Street, Cincinnati, OH 45220. Phone: 513-559-5061; FAX: 513-559-5646.

Received for publication 2 September 1994 and in revised form 13 January 1995.

1. Abbreviations used in this paper: MSG, major surface glycoprotein; SCID, severe combined immunodeficiency.

The Journal of Clinical Investigation, Inc.

Volume 95, June 1995, 2587-2593 nii-infected nude mice enhanced clearance of pneumocystosis. Other studies have shown that $\boldsymbol{P}$. carinii-infected severe combined immunodeficiency (SCID) ${ }^{1}$ mice reconstituted with spleen cells isolated from immunocompetent mice were able to resolve the infection (4). Further work using SCID mice demonstrated that reconstitution with $\mathrm{CD}^{+}$cells resulted in complete clearance of $P$. carinii from the lung (5). These data suggest the importance of adoptive transfer of immunocompetent cells in the clearance of $P$. carinii pneumonia. The role, if any, that specific $P$. carinii antigens play in this process has not yet been investigated.

Much of the immunological work on $P$. carinii has focused on a major surface glycoprotein referred to as MSG or gpA. MSG, which actually represents a family of related proteins encoded by unique genes (6-9), is highly immunogenic and elicits both humoral and cellular immune responses (10-14). It has been demonstrated that MSG is a specific $\mathbf{T}$ cell antigen and significantly increases the percentage of $\mathrm{CD} 4^{+} \mathrm{T}$ cells during the proliferative response (14). MSG also elicits the secretion of cytokines, suggesting the importance of this antigen in host T cell recognition of $P$. carinii by recruitment of inflammatory cells and cytokine production.

In the present study, we have tested the hypothesis that MSG contains epitopes which can elicit a protective cellular immune response. Since MSG has been shown to stimulate an immune response in exposed subjects, protective epitopes contained in this antigen might become attractive as vaccine targets. The secondary aim of this study was to determine whether the corticosteroid-treated rat could be used to analyze this immune recognition and clearance of $P$. carinii from the lungs.

\section{Methods}

Animals. Male Lewis rats (viral antibody-positive) were bred and raised in a conventional colony with food and water ad lib. at the Veterans Affairs Medical Center, Cincinnati, $\mathrm{OH}$ with ample environmental exposure to $P$. carinii. At 6-8 wk of age, $150-200 \mathrm{~g}, P$. carinii infection was induced by subcutaneous injections of $4 \mathrm{mg} / 0.4 \mathrm{ml}$ DepoMedrol (The Upjohn Co., Kalamazoo, MI) every seventh day. Ampicillin $(1 \mathrm{mg} / \mathrm{ml})$ was given in the water to control secondary bacterial infections. After 7 wk of immunosuppression, animals received the donor cells and continued on corticosteroid treatment for $10 \mathrm{wk}$. At this time, animals were killed by an overdose of $\mathrm{CO}_{2}$ and the lungs removed as described below. In each experiment, at least 10 animals were in each treatment group. Effectiveness of the adoptive transfer was based on histologic and quantitative analysis of the severity of $P$. carinii infection rather than on survival because some rats died from causes unrelated to $P$. carinii (e.g., other opportunistic infections, injection procedure). Only animals that survived $10 \mathrm{~d}$ after adoptive transfer were included in the data analysis.

Antigen preparation. After 8-10 wk of immunosuppression, $P$. carinii organisms were isolated from the lungs of corticosteroid-treated 
Sprague-Dawley rats as described (14). Briefly, lungs were removed, minced, and ground through a 60-mesh wire screen in PBS. Erythrocytes were lysed by exposure to $0.85 \%$ ammonium chloride, centrifuged, and the pellet washed twice with PBS. Samples of homogenates were streaked on Mueller-Hinton and Sabouraud dextrose agar plates for detection of any bacterial or fungal contaminants. Specimens with no detectable contamination were pooled and digested with Zymolyase 100 T (ICN Biomedicals Inc., Costa Mesa, CA) for $30 \mathrm{~min}$ at room temperature. The treated organisms were then fractionated by differential centrifugation. MSG was purified from the $100,000 \mathrm{~g}$ supernatant by HPLC. MSG was isolated on the basis of size by injecting 100,000 $g$ supernatants onto a Macrosphere GPC 150 column (Alltech Associates Inc., Deerfield, $\mathrm{IL})$ under isocratic conditions in $0.1 \mathrm{M} \mathrm{KH}_{2} \mathrm{PO}_{4}(\mathrm{pH}$ 7.0), $0.2 \mathrm{M} \mathrm{NaCl}$ as previously described (14). MSG migrated as a band with a molecular weight of $120 \mathrm{kD}$ on SDS-PAGE under reducing conditions. The purity of the preparation was shown by the following: Coomassie blue staining; reactivity with MSG-specific monoclonal antibodies; and by the absence of endotoxin, as verified by the Limulus amebocyte assay $(<0.125 \mathrm{U} / \mathrm{ml}$; Whittaker M. A. Bioproducts, Walkersville, MD).

Donor cell culture and transfer. In each adoptive transfer experiment, donor spleen cells were isolated from two groups of six adult Lewis rats. The first group of animals was born and raised in a protected environment free from exposure to common viruses and $P$. carinii. The second age-matched group consisted of animals raised in a conventional colony providing sufficient environmental exposure to $P$. carinii. In all cases, the presence or absence of antibodies to MSG was confirmed by Western blot analysis of sera. Spleens were obtained from both sets of animals and cells dispersed into PBS by passage through a stainless steel screen. Erythrocytes were lysed by incubation in $0.85 \%$ ammonium chloride, the cells washed twice in PBS, and then plated in RPMI 1640 containing $2 \mathrm{mM}$ L-glutamine, $100 \mathrm{U}$ of penicillin $/ \mathrm{ml}, 100 \mu \mathrm{g}$ of streptomycin $/ \mathrm{ml}, 5 \times 10^{-5} \mathrm{M} \beta$-mercaptoethanol, and $10 \%$ heatinactivated FCS. Cells were cultured for 1-7 d in the presence of MSG $(10 \mu \mathrm{g} / \mathrm{ml})$ or ovalbumin $(10 \mu \mathrm{g} / \mathrm{ml})$ to act as a nonspecific protein control. After culture, the cells were harvested and washed by centrifugation. Additionally, in one experiment, a standard proliferation assay was performed on the donor cells as previously described (14). Viability was determined by trypan blue dye exclusion $(\geq 96 \%)$. Cells were injected intravenously in $200-\mu \mathrm{l}$ vol into the tail vein of recipient Lewis rats that had undergone immunosuppression for $7 \mathrm{wk}$. In each experiment, all recipient animals received donor cells from the same splenocyte preparation with the intravenous injections administered 3-5 d apart, depending on the length of incubation time of the donor cells. In all cases, recipient animals continued on corticosteroid treatment for the full 10-wk period after adoptive transfer. Control animals received an injection of an equal volume of pyrogen-free normal saline.

Separation and FACS ${ }^{\otimes}$ analysis of cell populations. In one set of experiments, donor spleen cells were separated into distinct $\mathrm{CD}^{+}$and $\mathrm{CD}^{+}$cell populations before adoptive transfer. Cells were harvested following a 4-d incubation and separated using Cellect-plus Rat CD4 ${ }^{+}$ or $\mathrm{CD}^{+}$affinity chromatography (BioTex Laboratories, Edmonton, Canada) according to the manufacturer's instructions. The spleen cell suspensions were preincubated with either monoclonal mouse anti-rat $\mathrm{CD}^{+}$(for $\mathrm{CD}^{+}$purification) or monoclonal mouse anti-rat $\mathrm{CD} 4^{+}$ (for $\mathrm{CD}^{+}$purification) on ice for $1 \mathrm{~h}$. Cells were washed twice in pyrogen-free PBS and cell concentration adjusted to $5 \times 10^{7}$ cells $/ \mathrm{ml}$ before loading onto the column. Purified populations of CD4 ${ }^{+}$or $\mathrm{CD} 8{ }^{+}$ cells were eluted in the flow-through from the columns. Samples from each purification were analyzed for purity before adoptive transfer.

Sample purity and percentage of subpopulations of $T$ cells after incubation for 1-4 $d$ with and without MSG were analyzed by FACS ${ }^{\circledR}$ analysis (Becton Dickinson and Co., Mountain View, CA). Briefly, $10^{6}$ cells in $50 \mu \mathrm{l}$ were incubated with a fluorescein-conjugated mouse antirat $\mathrm{CD8}^{+} \mathrm{mAb}$ (PharMingen, San Diego, CA) and/or phycoerythrinconjugated mouse anti-rat $\mathrm{CD} 4^{+} \mathrm{mAb}$ (PharMingen) at $4^{\circ} \mathrm{C}$ for 20 min, washed three times in cold HBSS, and analyzed by flow microflu- orometry as previously described (15). Purity of each subset was $>92 \%$; however, the remaining $8 \%$ showed no detectable contamination by the alternate subset of $T$ cells.

Evaluation of $P$. carinii. Assessment of $P$. carinii in the lungs was based on histologic and quantitative procedures previously reported in detail (16). A highly significant correlation was found by both methods of assessment. At death or time of killing, the lungs were removed and weighed. The left lung of each animal was infused with a $4 \%$ formaldehyde solution until fully expanded and fixed further in formaldehyde for several days before conventional paraffin embedding. Three horizontal $0.5-\mu \mathrm{M}$ sections of the lung were stained with hematoxylin and eosin and Grocott-Gomori methenamine-silver. The lung sections were coded and read blindly. The following scoring system was used to evaluate $P$. carinii based on alveolar involvement: 0 , no infection; 0.5 , minimal ( $<1 \%$ alveoli); 1 , light $(1-25 \%$ alveoli); 2 , moderate (26$50 \%$ alveoli); 3 , severe ( $51-75 \%$ alveoli); and 4 , very severe ( $>75 \%$ alveoli)

The right lung was used for quantitation of $P$. carinii cysts and nuclei as described by Cushion and Walzer (17). Lung pieces were minced and then homogenized by passage through a stainless steel 60 mesh screen. The homogenate was centrifuged at $1,000 \mathrm{~g}$ at $4^{\circ} \mathrm{C}$, for $15 \mathrm{~min}$. The supernatant was decanted and erythrocytes lysed by incubation in $0.85 \% \mathrm{NH}_{4} \mathrm{Cl}$. The organisms were then washed twice in PBS and slides were prepared for enumeration. Stains used to identify $P$. carinii were cresyl echt violet (CEV), which selectively stains the cell wall of the cyst, and Diff-Quik (DQ), which stains the nuclei of cysts, trophozoites, and intermediate forms. Three 10- $\mu 1$ drops were placed on a glass slide and stained with either CEV or DQ. Each drop covered $\sim 1 \mathrm{~cm}^{2} .10$ oil immersion fields in each drop were randomly scanned. The lower limit of detection by this evaluation method is $1.1 \times 10^{5}$ organisms per lung. Cyst counts were performed routinely; Diff-Quik counts were performed in selected instances. Specimens to be studied were coded and read in a blind manner.

Statistical analysis. Data are reported as the log transformation of the geometric mean \pm SD. Scalar comparisons were made by ANOVA using the Newman-Keuls multiple range test or Student's $t$ test. Ordinal comparisons were made by the Mann-Whitney or the Wilcoxin-paired sample test as appropriate by INSTAT (GraphPAD Software for Science, San Diego, CA). Significance was accepted when the $P$ value $<0.05$.

\section{Results}

Adoptive transfer of $P$. carinii-exposed or unexposed lymphocytes. In the first experiment, we compared the effectiveness of administering donor spleen cells from Lewis rats with exposure to $P$. carinii; donor spleen cells from unexposed (naive) rats; or saline in the clearance of $P$. carinii pneumonia among recipient animals (Fig. 1). The $\log _{10}$ mean $P$. carinii cyst count among rats administered saline $(9.29 \pm 0.35 /$ lung $)$ was very similar to the cyst counts for all groups of recipients administered splenocytes from naive animals (ranging from 8.92 $\pm 0.69 /$ lung to $9.08 \pm 0.25 /$ lung $)$. By contrast, a significant $(P<0.05)$ reduction in cyst counts was achieved in recipients administered splenocytes from rats which had been exposed to $P$. carinii; these groups included fresh cells and cells incubated for $24 \mathrm{~h}$ in the presence or absence of MSG or ovalbumin (ranging from $8.04 \pm 0.55 /$ lung to $8.46 \pm 0.67 /$ lung). Among each of these groups, a significantly lower $(P<0.05) \log _{10}$ mean cyst count was achieved with the administration of exposed splenocytes than with the unexposed splenocytes. When the recipients administered the exposed spleen cells were compared, the greatest reduction was obtained with cells incubated with MSG (8.04 $\pm 0.55 /$ lung). However, the differences among these groups were not statistically significant. 


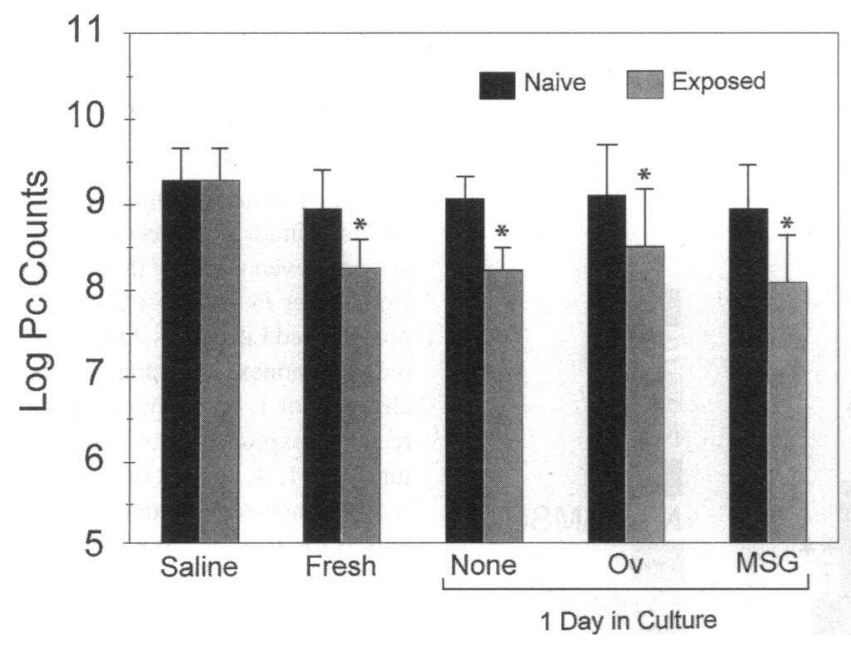

Figure 1 . The effects of $P$. carinii-exposed vs naive donor spleen cells in the clearance of pneumocystosis in recipient Lewis rats. Two groups of immunosuppressed Lewis rats were reconstituted at week seven with $10^{6}$ freshly isolated donor cells from either $P$. carinii-exposed Lewis rats or nonexposed rats. Two groups received $10^{6}$ donor cells from exposed or naive Lewis rats which had been in culture for $24 \mathrm{~h}$. Two groups received $10^{6}$ exposed or naive donor cells pulsed with ovalbumin $(O v)$ for $24 \mathrm{~h}$. Two groups received similar numbers of donor cells which had been pulsed for $24 \mathrm{~h}$ with MSG, and one group received only saline. Raw numbers for quantitation of $P$. carinii organisms were obtained by staining lung homogenates with cresyl echt violet. Cyst counts are reported as the $\log$ transformation of the geometric mean \pm SD. ${ }^{*} P<0.05$ compared to the saline injection control and/or spleen cells from unexposed rats.

Our previous reports showed that $P$. carinii nucleus counts are usually higher than cyst counts and respond to antimicrobial drugs in a similar manner (16). In the present study, nucleus counts were 4-10-fold higher than cyst counts and exhibited comparable responses in adoptive transfer experiments.

Adoptive transfer of MSG-pulsed lymphocytes. In this study, we investigated the effects of different times of incubation with MSG on the clearance of the organism (Fig. 2). After $1 \mathrm{~d}$ of incubation, regardless of the presence of MSG, there were no significant differences in the $\log _{10}$ mean cyst count among rats administered saline $(9.18 \pm 0.41 /$ lung $)$ and those animals receiving unexposed splenocytes (ranging from 9.06 $\pm 0.26 /$ lung to $8.92 \pm 0.38 /$ lung). However, recipients administered $P$. carinii-exposed donor cells alone and incubated with MSG had significantly $(P<0.05)$ lower $\log _{10}$ mean cyst counts of $8.21 \pm 0.25 /$ lung and $8.08 \pm 0.52 /$ lung, respectively. The difference in organism counts among these two groups was not statistically significant.

After the 4-d incubation, no significant difference was present between animals receiving saline compared to those rats administered naive donor cells incubated with or without MSG (ranging from $8.76 \pm 0.4 /$ lung to $8.99 \pm 0.52 /$ lung). In contrast, the $\log _{10}$ mean cyst count for rats administered exposed donor cells incubated for $4 \mathrm{~d}$ in the absence of MSG was significantly $(P<0.05)$ reduced $(8.11 \pm 0.48 /$ lung $)$. An even more significant $(P<0.001)$ decline was observed in the recipients rats administered exposed donor cells pulsed for $4 \mathrm{~d}$ with MSG (7.22 $\pm 0.33 /$ lung). This reduction was also significantly $(P<$ $0.05)$ greater than that achieved with the exposed cells alone.
Incubation of the splenocytes from exposed rats for $7 \mathrm{~d}$ in culture produced results similar to those obtained with cells incubated for $4 \mathrm{~d}$. A highly significant $(P<0.001)$ reduction in $P$. carinii cyst counts was achieved with spleen cells pulsed with MSG.

To investigate the properties of these donor cells before adoptive transfer, aliquots of the whole spleen cell suspensions from both naive and exposed animals were examined for their in vitro proliferative response to MSG and their cellular composition. Peak proliferative response to MSG by $P$. cariniiexposed $\mathrm{T}$ cells occurs after a 4-d incubation with the antigen (14). As shown in Table I, only spleen cells from exposed animals displayed a significant proliferative response $(39,600 \pm 6,200$ mean cpm, $P<0.05)$ to MSG compared to the values obtained from media alone. All four of the experimental groups displayed normal frequencies of $\mathrm{CD} 4^{+}$and $\mathrm{CD} 8{ }^{+}$populations after $1 \mathrm{~d}$ of incubation; yet, by day four of incubation, these groups had elevated levels of $\mathrm{CD} 4^{+}$cells. This change was most marked with exposed $\mathrm{CD}^{+}$cells pulsed with MSG which increased from $46 \pm 4 \%$ at $1 \mathrm{~d}$ to $72 \pm 3 \%$ at $4 \mathrm{~d}$. In contrast to the $\mathrm{CD}^{+}{ }^{+}$cells, there was no difference in the frequency of $\mathrm{CD}^{+}$cells in any of the groups despite time of incubation.

Adoptive transfer of lymphocyte subsets. Based on the previous observations, to determine if a specific $\mathrm{T}$ cell subset provided the reduction of $P$. carinii burden observed, the donor cells were separated into $\mathrm{CD}^{+}{ }^{+}$and $\mathrm{CD}^{+}$populations after a 4-d incubation in the presence or absence of MSG. As shown in Fig. 3, rats administered whole spleen cells after the 4-d incubation had cyst counts similar to those previously observed. There was no significant difference in the $\log _{10}$ mean cyst counts among rats administered saline $(9.2 \pm 0.13 /$ lung $)$ and those recipients administered naive donor splenocytes pulsed for $4 \mathrm{~d}$ with MSG (8.76 $\pm 0.4 /$ lung). Animals administered exposed splenocytes had significantly $(P<0.05)$ lower mean cyst counts (8.07 $\pm 0.52 /$ lung), while the most significant $(P$ $<0.001)$ reduction was observed in the recipients administered exposed splenocytes pulsed with MSG $(7.17 \pm 0.36 /$ lung). In contrast to the whole spleen cells, a significant reduction in the $\log _{10}$ mean cyst count was observed in all recipient animals receiving $\mathrm{CD}^{+}{ }^{+}$donor cells. These groups included unexposed $\mathrm{CD}^{+}{ }^{+}$cells pulsed for $4 \mathrm{~d}$ with $\mathrm{MSG}$ (8.2 $\pm 0.63 /$ lung, $P$ $<0.05$ ), exposed CD4 ${ }^{+}$cells $(6.99 \pm 0.58 /$ lung, $P<0.001)$, and exposed CD $4^{+}$cells pulsed for $4 \mathrm{~d}$ with MSG $(5.93 \pm 0.77 /$ lung, $P<0.001)$. These data suggest that $\mathrm{CD} 4^{+}$cells, regardless of origin or sensitization, are important in protection. However, an $\sim 10$-fold difference existed between each of the treatment groups, with MSG-pulsed $\mathrm{CD}^{+}{ }^{+}$cells isolated from exposed animals being the most effective in reducing the $\log _{10}$ mean of $P$. carinii cysts. After reconstitution with $\mathrm{CD}^{+}$cells, a significant $(P<0.05)$ reduction in the mean cyst count was observed only in the recipient rats administered exposed $\mathrm{CD} 8{ }^{+}$ cells $(8.29 \pm 0.27 /$ lung $)$. No further reduction in the $\log _{10}$ mean cyst count by the $\mathrm{CD}{ }^{+}$cells was obtained after incubation with MSG (8.32 $\pm 0.12 /$ lung).

Histological analysis. Evaluation of the magnitude of $P$. carinii pneumonia and the effects of the adoptive transfer of the different donor cell groups by histological scoring correlated well with the data obtained by organism quantitation (Table II). The hematoxylin and eosin-stained sections of the lungs from animals receiving saline or naive donor cells revealed the typical foamy intraalveolar exudate with only a mild infiltration 


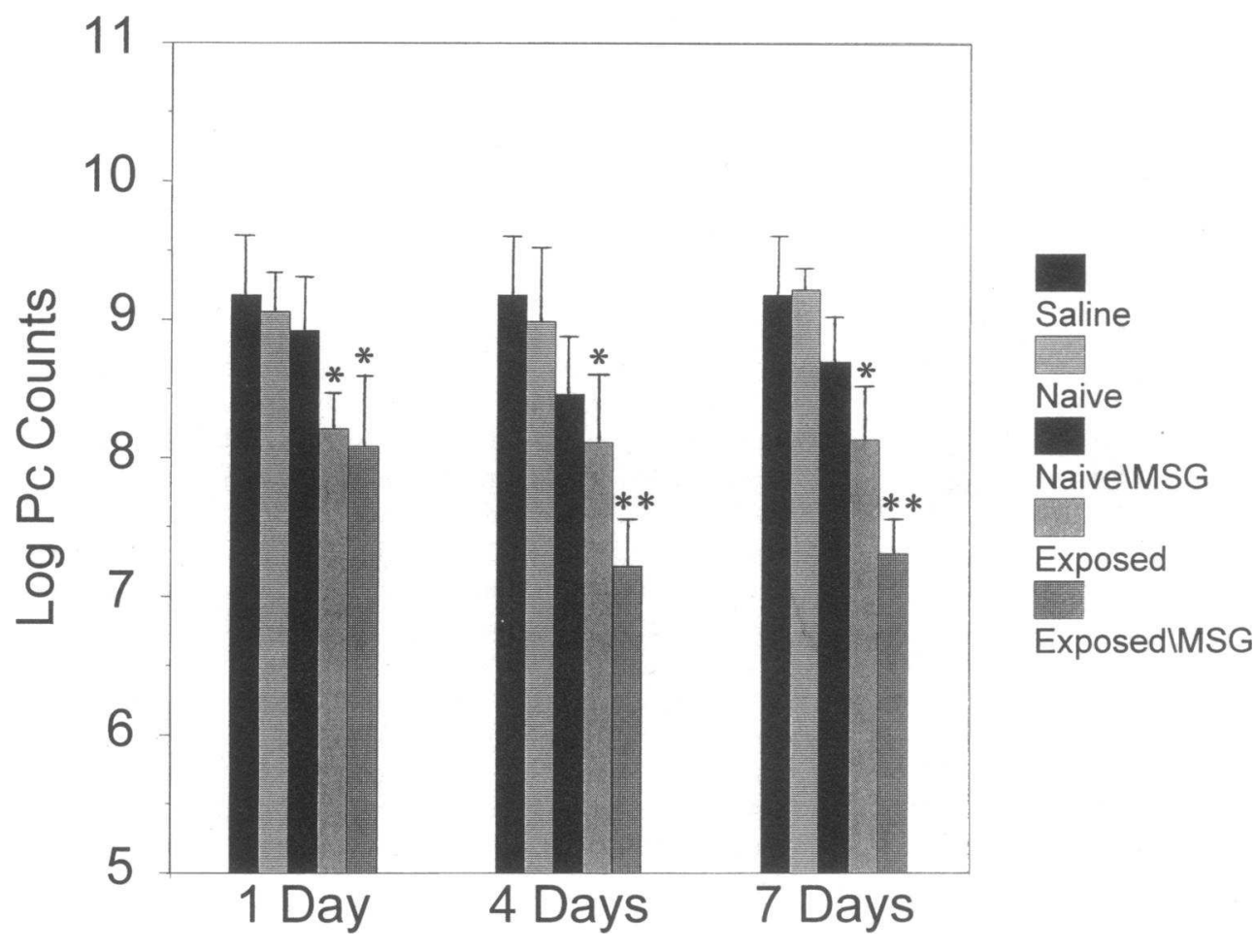

Figure 2. The effects of $P$. carinii-exposed or nonexposed donor cell incubation time with MSG on the clearance of pneumocystosis in recipient Lewis rats. Four groups of immunosuppressed Lewis animals were reconstituted at week seven with $10^{6}$ donor cells from either $P$. carinii-exposed or nonexposed Lewis rats. One group received nonexposed donor cells cultured for 1,4 , or $7 \mathrm{~d}$; one group received exposed donor cells cultured for 1,4 , or $7 \mathrm{~d}$; one group received nonexposed donor cells pulsed for 1,4 , or $7 \mathrm{~d}$ with MSG; one group received exposed donor cells pulsed for 1,4 , or $7 \mathrm{~d}$ with MSG; and one group received only saline. Raw numbers for quantitation of $P$. carinii cysts were obtained by staining lung homogenates with cresyl echt violet. Counts are reported as log transformation of the geometric mean \pm SD. ${ }^{*} P<0.05$ compared to saline injection control. $* * P$ $<0.001$ compared to saline injection control. of alveolar macrophages. Examination of alveoli by silver staining revealed that a high percentage of the alveoli were involved in the infection $(3.4 \pm 0.6)$ with cysts closely aggregated and clustered in the center of the exudate in these groups. The lungs from animals receiving exposed donor cells pulsed for 4 and 7 d exhibited significantly $(P<0.05)$ lower histological scores of $2.2 \pm 0.6$ and $2.4 \pm 0.4$, respectively. The results of these cell transfers were also seen in changes in the lung weight to body weight ratio, which has previously been shown to correlate well with histologic score and $P$. carinii organism burden (16).

Mortality and the hyperinflammatory response with $C D 4^{+}$ cells. Earlier reports have shown that reconstitution of SCID mice with $\mathrm{CD} 4{ }^{+}$cells from a $P$. carinii-immunized or environmentally exposed donor results in an early hyperinflammatory reaction which leads to an increase in mortality (5). This extreme hyperinflammatory response was characterized by an increase in lung weight. In the present study, adoptive transfer of exposed $\mathrm{CD}^{+}$cells pulsed with MSG resulted in the lowest histologic score $(1.6 \pm 0.5)$, but the highest lung weight to body weight ratio $(18 \pm 2)$ of all rat groups (Table II). The results suggested that the $\mathrm{CD}^{+}$cells were effective in clearing $P$. carinii but caused a hyperinflammatory response which was responsible for the premature death of five rats. This conclusion was supported by histologic analysis which showed heavy infil-

Table I. Properties of Lewis Rat Donor Cells before Adoptive Transfer

\begin{tabular}{|c|c|c|c|c|c|c|}
\hline & \multicolumn{2}{|c|}{${ }^{3}[\mathrm{H}]$ thymidine uptake } & \multicolumn{2}{|c|}{ Positive $\mathrm{CD}^{\ddagger}$} & \multicolumn{2}{|c|}{ Positive CD8 ${ }^{\ddagger}$} \\
\hline & \multicolumn{2}{|c|}{$\mathrm{cpm} \times 10^{-3}$} & \multicolumn{2}{|c|}{$\%$} & \multicolumn{2}{|c|}{$\%$} \\
\hline & $1 \mathrm{~d}$ & $4 d$ & $1 \mathrm{~d}$ & $4 \mathrm{~d}$ & $1 \mathrm{~d}$ & $4 \mathrm{~d}$ \\
\hline \multicolumn{7}{|c|}{ Experiment groups } \\
\hline Naive & $1.5 \pm 0.3$ & $1.2 \pm 0.4$ & $39 \pm 2$ & $48 \pm 5$ & $21 \pm 2$ & $20 \pm 2$ \\
\hline Exposed & $1.6 \pm 0.2$ & $1.1 \pm 0.3$ & $41 \pm 3$ & $54 \pm 4$ & $18 \pm 2$ & $19 \pm 2$ \\
\hline Naive & $2.5 \pm 0.7$ & $5.8 \pm 1.5$ & $43 \pm 1$ & $62 \pm 5$ & $20 \pm 2$ & $17 \pm 3$ \\
\hline Exposed & $7.9 \pm 1.7$ & $39.6 \pm 6.2$ & $46 \pm 4$ & $72 \pm 3$ & $16 \pm 2$ & $19 \pm 1$ \\
\hline
\end{tabular}

\footnotetext{
* Whole spleen cell suspensions from naive and $P$. carinii-exposed Lewis rats were incubated in RPMI 1640 complete with and without MSG (10 $\mu \mathrm{g} / \mathrm{ml}$ ) for 1 or $4 \mathrm{~d}$. After this incubation, the cells were pulsed overnight with $1 \mu \mathrm{Ci} /$ well $\left[{ }^{3} \mathrm{H}\right]$ thymidine before harvest on glass fiber filter strips. Samples were than counted by liquid scintillation counting. Data are expressed as mean $\mathrm{cpm} \pm \mathrm{SD}$ of triplicate cultures of a representative experiment. ${ }^{\ddagger}$ Whole spleen cell suspensions from naive or $P$. carinii-exposed Lewis rats were incubated in RPMI 1640 complete with and without MSG (10 $\mu \mathrm{g} / \mathrm{ml}$ ) MSG for 1 or $4 \mathrm{~d}$. Surviving cells were isolated over Ficoll-Hypaque and stained with Fluorescein-conjugated mouse anti-rat CD8 and phycoerythrin-conjugated mouse anti-rat CD4. Cells were analyzed by flow microfluorometry in a fluorescence-activated cell sorter.
} 


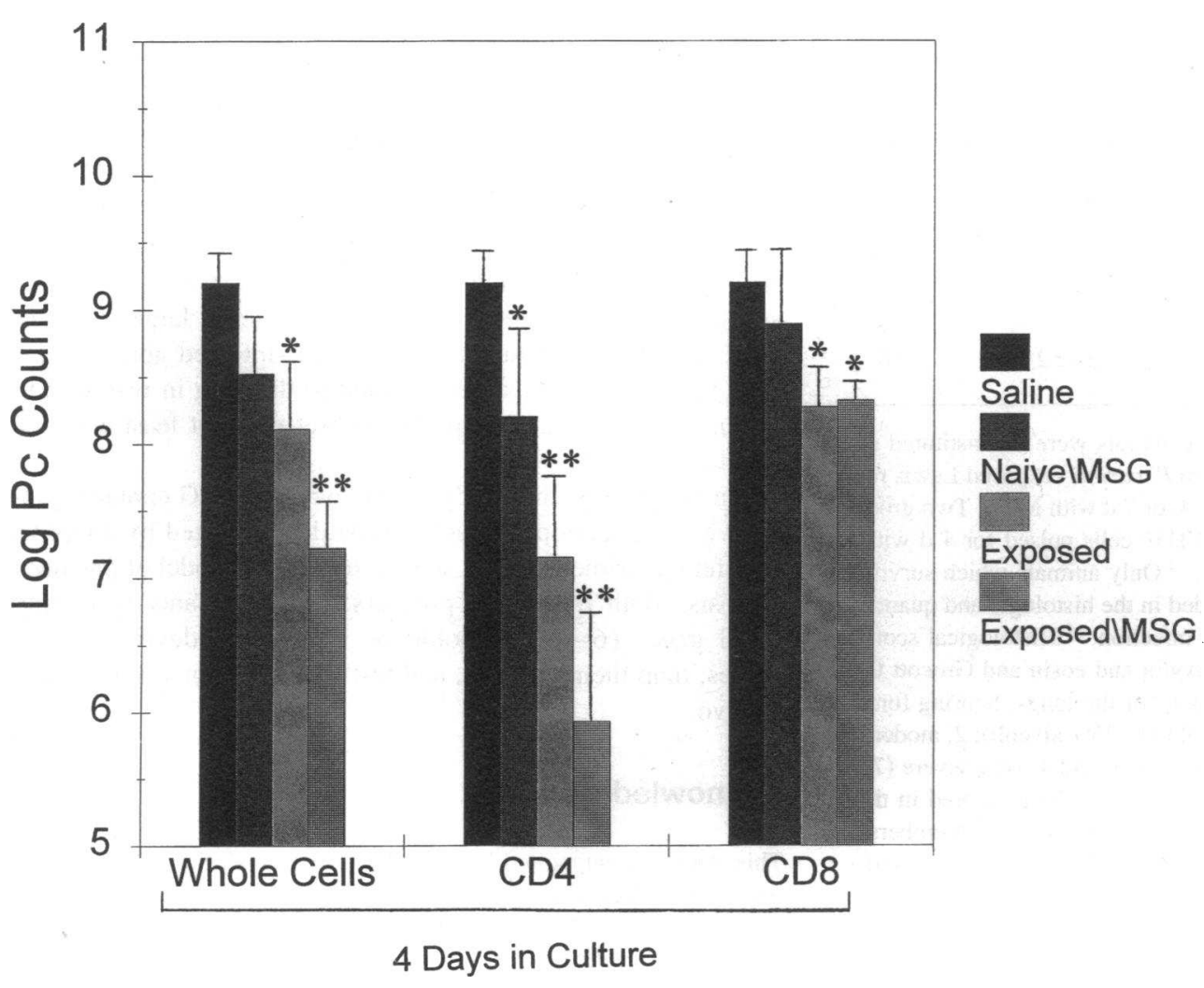

Figure 3. The effects of purified lymphocyte subsets on the clearance of pneumocystosis in recipient Lewis rats. Immunosuppressed Lewis rats were reconstituted at week seven with donor cells from $P$. carinii-exposed or nonexposed Lewis rats. One group received $10^{6}$ naive donor cells pulsed for 4 d with MSG; one group received $10^{6}$ exposed donor cells cultured for $4 \mathrm{~d}$; one group received $10^{6}$ exposed donor cells pulsed for 4 d with MSG; two groups received either $10^{6}$ purified nonexposed $\mathrm{CD}^{+}{ }^{+}$or $\mathrm{CD}^{+}{ }^{+}$cells pulsed for 4 d with MSG; two groups received either $10^{6}$ purified exposed CD8 ${ }^{+}$ or $\mathrm{CD}^{+}{ }^{+}$cultured for $4 \mathrm{~d}$; two groups received either $10^{6}$ purified exposed $\mathrm{CD}^{+}$or $\mathrm{CD} 4^{+}$cells pulsed for $4 \mathrm{~d}$ with MSG; and one group received only saline. Raw numbers for quantitation of $P$. carinii cysts were obtained by staining lung homogenates with cresyl echt violet. Cyst counts are reported as $\log$ transformation of the geometric mean $\pm \mathrm{SD} . * P$ $<0.05$ compared to saline injection control. $* * P<0.001$ compared to saline injection control. trates with mononuclear cells and alveolar macrophages within the lungs. By contrast, the three rats which survived this episode had a lung weight to body weight ratio of $9 \pm 2$ and the lungs, which were cleared of $P$. carinii, had normal histology.

\section{Discussion}

Results described in this paper represent the first demonstration that MSG contains protective $\mathrm{T}$ cell epitopes. This protective response observed after adoptive transfer of the donor cells was dependent on previous exposure to $P$. carinii and time of incubation with MSG. The effect was specific for MSG, as demonstrated by the lack of clearance in the lungs of animals receiving donor cells incubated with an equivalent concentration of ovalbumin.

The role of MSG in recognition of and immune response to $P$. carinii has yet to be fully elucidated. Gigliotti et al. (18), using immunoelectron microscopy, demonstrated that MSG is distributed on the surface of all developmental stages of $P$. carinii. Through molecular studies of rat and ferret $P$. carinii, it has been demonstrated that MSG represents a group of proteins encoded by multiple genes $(6-8,19)$. Numerous unique MSG cDNAs have been identified, establishing that multiple mRNAs are transcribed within a population of organisms (6-9). These data raise the possibility that antigenic variation may occur in MSG as a means of evading the host immune defenses. The present report has shown that native MSG can elicit a protective immune response. Further studies with different recombinant MSG preparations are needed to identify conserved, protective epitopes before consideration can be given to MSG as a potential vaccine candidate.

Protection against $P$. carinii in the present study was achieved with the adoptive transfer of sensitized whole spleen cell suspensions and purified $\mathrm{CD}^{+}$cells, regardless of their origin or previous sensitization. Several methods have been utilized in vivo to demonstrate the critical role $\mathrm{CD}^{+}{ }^{+}$cells have in resistance to $P$. carinii pneumonia. Shellito et al., (20) utilized $\mathrm{CD}^{+}{ }^{+}$-depleted mice which, after intratracheal inoculation, developed a vigorous $P$. carinii infection that was cleared after repletion of these cells. Using the SCID mouse model, Harmsen and Stankiewicz (4) demonstrated that reconstitution of these mice with immunocompetent spleen cells resulted in clearance of $P$. carinii. In the same study, treatment of the reconstituted animals with an anti-CD4 ${ }^{+}$monoclonal antibody resulted in the inability to resolve the infection. Similarly, Roth and Sidman (5), also using the SCID model, showed that adoptive transfer of $\mathrm{CD}^{+}{ }^{+}$cells was sufficient for resistance; yet, this reconstitution caused an intense hyperinflammatory response, resulting in high mortality in the recipient mice.

The present study was performed using the standard corticosteroid-treated rat model of pneumocystosis. We were reluctant to attempt the adoptive transfer experiments using this model because of the broad effects of steroids on the host immune system. These actions include involution of all lymphoid tissues (21); suppression of T lymphocyte function (22), macrophage differentiation and function (23), natural killer activity (24), and antibody responses to $P$. carinii (25); and peripheral blood lymphopenia, which occurs through a process of cell redistribu- 
Table II. Histoligical Score, Lung Weight to Body Weight Ratio, and Percent Mortality of Lewis Rats after Adoptive Transfer of MSG-pulsed T Cells

\begin{tabular}{|c|c|c|c|c|}
\hline $\begin{array}{l}\text { Experimental } \\
\text { group* }\end{array}$ & $\begin{array}{c}\text { No. of } \\
\text { animals }^{\ddagger}\end{array}$ & $\begin{array}{l}\text { Histological } \\
\text { score }\end{array}$ & $\begin{array}{l}\text { Lung wt to } \\
\text { body wt" }\end{array}$ & $\begin{array}{c}\text { Premature } \\
\text { death' }\end{array}$ \\
\hline Saline & 14 & $3.4 \pm 0.6$ & $17 \pm 3$ & $4 / 14$ \\
\hline $1 \mathrm{~d}$ pulse & 10 & $2.8 \pm 0.8$ & $10 \pm 4 * *$ & $0 / 10$ \\
\hline $4 \mathrm{~d}$ pulse & 10 & $2.2 \pm 0.6 * *$ & $9 \pm 3 * *$ & $0 / 10$ \\
\hline $7 \mathrm{~d}$ pulse & 9 & $2.4 \pm 0.4 * *$ & $11 \pm 2 * *$ & $1 / 9$ \\
\hline $\mathrm{CD}^{+}$ & 8 & $2.8 \pm 0.4$ & $11 \pm 3 * *$ & $2 / 8$ \\
\hline $\mathrm{CD}^{+}{ }^{+}$ & 8 & $1.6 \pm 0.5^{* *}$ & $18 \pm 2$ & $5 / 8$ \\
\hline
\end{tabular}

* Five groups of immunosuppressed Lewis rats were reconstituted at week seven with donor spleen cells from $P$. carinii-exposed Lewis rats. Groups received $10^{6}$ cells pulsed for 1,4 , or $7 \mathrm{~d}$ with MSG. Two groups received either $10^{6}$ purified $\mathrm{CD}^{+}$or $\mathrm{CD}^{+}$cells pulsed for $4 \mathrm{~d}$ with MSG. One group received only saline. ${ }^{\ddagger}$ Only animals which survived $10 \mathrm{~d}$ after adoptive transfer were included in the histologic and quantitative analysis for severity of $P$. carinii infection. ${ }^{8}$ Histological score was determined by analysis of hematoxylin and eosin and Grocott Gomori methenamine-silver-stained sections of the lungs. Scoring for alveoli involvement: 0 , no infection; 1 , light (1-25\% alveoli); 2 , moderate (26-50\% alveoli); 3 , severe ( $51-75 \%$ alveoli); and 4 , very severe (76$100 \%$ alveoli). Values represent mean \pm SD of all lungs scored in the experiments. "Values represent mean ratio $\times 10^{3} \pm \mathrm{SD}$. ' Numbers represent animals that died between $10 \mathrm{~d}$ after adoptive transfer and week 10 of the experiment. ${ }^{* *}$ Significantly different compared to saline, $P<0.05$.

tion rather than cell destruction with the primary site of influx being the bone marrow $(15,26,27)$. Since at least a portion of the lymphocytes in the lung are derived from peripheral blood (28), we feared that corticosteroids might impeded recruitment of lymphocytes from the bone marrow to the lung. However, studies demonstrating the enhanced ability of $\mathrm{T}$ cell clones to survive and function in immunocompromised hosts suggested that steroid-treated rats might provide a permissive environment for adoptive transfer experiments $(29,30)$. Perhaps the intravenous injection of activated lymphocytes in our rats resulted in immediate recruitment of the donor cells to the lung, where they were sequestered at the sight of infection.

The treatment of $P$. carinii pneumonia with drugs or by immunological reconstitution has led to some unexpected results. In both our study and a previous study using the SCID mouse model $(5)$, reconstitution with $\mathrm{CD}^{+}$cells alone produced an extreme hyperinflammatory response resulting in deleterious effects to the host. This response occurred in our model despite the presence of steroids. In contrast, administration of corticosteroids to AIDS patients with pneumocystosis prevents the deterioration in blood oxygenation which occurs soon after beginning anti- $P$. carinii therapy; the hypothesis here is that the drug-induced damage to $P$. carinii exacerbates the lung's inflammatory response (31-34). It, thus, appears that the pathophysiologic mechanisms underlying the clinical deterioration in AIDS patients and rodents are different. $P$. carinii pneumonia causes significant changes in the lung surfactant system characterized by a fall in phospholipids and an increase in surfactant protein A (35). Since corticosteroids are known to increase surfactant phospholipids and cause other changes in the alveolar microenvironment $(36)$, it is possible that the beneficial effects of steroids in AIDS patients with $P$. carinii pneumonia are exerted through the surfactant system rather than through the host inflammatory response.

Although the data presented here indicate that $\mathrm{CD} 4^{+}$cells play a critical role in the immune response to $P$. carinii, the possible role for $\mathrm{CD}^{+}$cells has not been elucidated. $\mathrm{CD} 8^{+}$ cells offer some resistance to pneumocystosis after adoptive transfer (Fig. 3). In contrast to our findings, adoptive transfer of purified $\mathrm{CD}^{+}$cells into SCID mice was ineffective in clearance (5). Previous studies using the corticosteroid-treated rat and the $\mathrm{CD}^{+}{ }^{+}$-depleted mouse demonstrated a large influx of $\mathrm{CD}^{+}$cells into the lungs of $P$. carinii-infected animals (15, 37). Since $\mathrm{CD} 8^{+}$cells are recruited to the lung in response to $P$. carinii infection, perhaps this subset plays at least a partial role in clearance.

In conclusion, this study has shown that MSG contains protective $\mathrm{T}$ cell epitopes which can be demonstrated by adoptive transfer experiments in the steroid-treated rat model of pneumocystosis. With the recent progress in cloning and expressing MSG genes (6-9), it should be possible to develop $T$ cell clones, map their epitopes, and test their functional importance in vivo.

\section{Acknowledgments}

This study was supported by the Medical Research Service of the Department of Veterans Affairs, by Public Health Service contract AI25139, and grants HL-46653, AI 31702, and AI 32899 from the National Institutes of Health.

\section{References}

1. Walzer, P. D. 1993. Pneumocystis carinii: recent advances in basic biology and their clinical application. AIDS (Phila.). 7:1293-1305.

2. Bowen, D. L., H. C. Lane, and A. S. Fauci. 1985. Immunopathogenesis of the aquired immunodeficiency syndrome. Ann. Intern. Med. 103:704-709.

3. Furuta, T., K. Ueda, S. Kyuwa, and K. Fujiwara. 1984. Effect of T cell transfer on Pneumocystis carinii infection in nude mice. Jpn. J. Exp. Med. 54:5764.

4. Harmsen, A. G., and M. Stankiewicz. 1990. Requirement for CD4 ${ }^{+}$cells in resistance to Pneumocystis carinii pneumonia in mice. J. Exp. Med. 172:937945.

5. Roths, J. B., and C. L. Sidman. 1992. Both immunity and hyperresponsiveness to Pneumocystis carinii result from transfer of $\mathrm{CD}^{+}$but not $\mathrm{CD} 8^{+} \mathrm{T}$ cells into severe combined immunodeficiency mice. J. Clin. Invest. 90:673-678.

6. Kovacs, J. A., F. Powell, J. C. Edman, B. Lundgren, A. Martinez, B. Drew, and C. W. Angus. 1993. Multiple genes encode the major surface glycoprotein of Pneumocystis carinii. J. Biol. Chem. 268:6034-6040.

7. Linke, M. J., A. G. Smulian, J. R. Stringer, and P. D. Walzer. 1994 Characterization of multiple unique cDNAs encoding the major surface glycoprotein of rat-derived Pneumocystis carinii. Parasitol. Res. 80:478-486.

8. Sunkin, S. M., S. L. Stringer, and J. R. Stringer. 1994. A tandem repeat of rat-derived Pneumocystis carinii genes encoding the major surface glycoprotein. J. Eukaryot. Microbiol. 41:292-300.

9. Wada, M., K. Kitada, M. Saito, K. Egwaw, and Y. Nakamura. 1993. cDNA sequence diversity and genomic clusters of major surface glycoprotein genes of Pneumocystis carinii. J. Infect. Dis. 168:979-985.

10. Graves, D. C., S. J. McNabb, M. A. Worley, T. D. Downs, and M. H Ivey. 1986. Analyses of rat Pneumocystis carinii antigens recognized by human and rat antibodies by using western immunoblotting. Infect. Immun. 54:96-103.

11. Fisher, D. J., F. Gigliotti, M. Zauderer, and A. G. Harmsen. 1991. Specific T-cell response to a Pneumocystis carinii surface glycoprotein (gp 120) after immunization and natural infection. Infect. Immun. 59:3372-3376.

12. Walzer, P. D., D. Stanforth, M. J. Linke, and M. T. Cushion. 1987. Pneumocystis carinii: immunoblotting and immunofluorescent analyses of serum antibodies during experimental rat infection and recovery. Exp. Parasitol. 63:319328.

13. Walzer, P. D., C. K. Kim, M. J. Linke, C. L. Pogue, M. J. Huerkamp, C. E. Chrisp, A. V. Lerro, S. K. Wixson, E. Hall, and L. D. Shultz. 1989. Outbreaks 
of Pneumocystis carinii pneumonia in colonies of immunodeficient mice. Infect. Immun. 57:62-70.

14. Theus, S. A., M. J. Linke, R. P. Andrews, and P. D. Walzer. 1993. Proliferative and cytokine responses to a major surface glycoprotein of Pneumocystis carinii. Infect. Immun. 61:4703-4709.

15. Walzer, P. D., M. LaBine, T. J. Redington, and M. T. Cushion. 1984 Lymphocyte changes during chronic administration of and withdrawal from corticosteroids: relation to Pneumocystis carinii pneumonia. J. Immunol. 133:25022508.

16. Kim, C. K., J. M. Foy, M. T. Cushion, D. Stanforth, M. J. Linke, H. L. Hendrix, and P. D. Walzer. 1987. Comparison of histologic and quantitative techniques in evaluation of therapy for experimental Pneumocystis carinii pneumonia. Antimicrob. Agents Chemother. 31:197-201.

17. Cushion, M. T., and P. D. Walzer. 1984. Growth and serial passage of Pneumocystis carinii in the A549 cell. Infect. Immun. 44:245-251.

18. Gigliotti, F., D. C. Stokes, A. B. Cheatham, D. S. Davis, and W. T. Hughes. 1986. Development of murine monoclonal antibodies to Pneumocystis carinii. J. Infect. Dis. 154:315-322.

19. Gigliotti, F., L. R. Ballou, W. T. Hughes, and B. D. Mosley. 1988. Purification and initial characterization of a ferret Pneumocystis carinii surface antigen. J. Infect. Dis. 1558:848-854.

20. Shellito, J., V. V. Suzara, W. Blumenfeld, J. M. Beck, H. J. Steger, and T. H. Ermak. 1990. A new model of Pneumocystis carinii infection in mice selectively depleted of helper T lymphocytes. J. Clin. Invest. 85:1686-1693.

21. Walzer, P. D., M. LaBine, T. J. Redington, and M. T. Cushion. 1984 Predisposing factors in Pneumocystis carinii pneumonia: effects of tetracycline, protein malnutrition, and corticosteroids on hosts. Infect. Immun. 46:747-753.

22. Claman, H. N., J. W. Moorehead, and W. H. Benner. 1971. Corticosteroids and lymphoid cells in vitro. I. Hydrocortisone lysis of human, guinea pig, and mouse thymus cells. J. Lab. Clin. Med. 78:499-507.

23. Fauci, A. S., and D. C. Dale. 1974. The effect of in vivo hydrocortisone on subpopulations of human lymphocytes. J. Clin. Invest. 53:240-246.

24. Hatton, T., F. Hirata, T. Hoffman, A. Hizuta, and R. B. Herberman 1982. Inhibition of human natural killer activity and antibody dependent cellular cytotoxicity by lipomodulin, a phospholipase inhibitory protein. J. Immunol. 131:662-665.

25. Walzer, P. D., and M. E. Rutledge. 1981. Humoral immunity in experimental Pneumocystis carinii infection. J. Lab. Clin. Med. 97:820-833.
26. Berney, S. 1974. Characterization of glycocorticosteroid-induced changes in lymphocyte circulation in the rat. Clin. Res. 22:141a. (Abstr.)

27. Brahim, F. 1978. Marrow lymphocyte production during chronic hydrocortisone administration. J. Reticuloendothel. Soc. 23:111-116.

28. Emeson, E. E., A. J. Norin, and F. J. Veith. 1982. Antigen-induced recruitment of circulating lymphocytes to the lungs and hilar lymph nodes of mice challenged intratracheally with alloantigens. Am. Rev. Respir. Dis. 125:453459.

29. Henderson, H. M., and G. S. Deepe. 1992. Recognition of Histoplasma capsulatum yeast-cell antigens by human T-cell clones. J. Leuk. Biol. 51:432436.

30. Riddell, S. R., K. S. Watanabe, J. M. Goodrich, C. R. Li, M. E. Agha, and P. D. Greenberg. 1992. Restoration of viral immunity in immunodeficien humans by the adoptive transfer of T cell clones. Science (Wash. DC). 257:238241

31. Montaner, J. S. G., L. M. Lawson, N. Levitt, A. Belzberg, M. T. Schechter and J. Ruedy. 1990. Corticosteroids prevent early. deterioration in patients with moderately severe Pneumocystis carinii pneumonia and the acquired immunodeficiency syndrome (AIDS). Ann. Intern. Med. 113:14-20.

32. Bozzette, S. A., F. R. Sattler, J. Chiu, and A. W. Wu. 1990. A controlled trial of early adjunctive treatment with corticosteroids for Pneumocystis carini pneumonia in the acquired immunodeficiency syndrome. N. Engl. J. Med. 323:1451-1457.

33. Masur, H. 1992. Prevention and treatment of Pneumocystis pneumonia. N. Engl. J. Med. 327:1853-1860.

34. National Institutes of Health-University of California Expert Panel for Corticosteroids as Adjunctive Therapy for Pneumocystis carinii Pneumonia. 1990 Consensus statement on the use of corticosteroids as adjunctive therapy for pneumocystosis pneumonia in the acquired immunodeficiency syndrome. $N$. Engl. $J$. Med. 323:1500-1504.

35. Phelps, D. S., and R. M. Rose. 1991. Increased recovery of surfactant protein A in AIDS-related pneumonia. Am. Rev. Respir. Dis. 143:1072-1075.

36. Rice, W. R., F. M. Singleton, M. J. Linke, and P. D. Walzer. 1993. Regulation of surfactant phosphatidylcholine secretion from alveolar type II cells during Pneumocystis carinii pneumonia in the rat. J. Clin. Invest. 92:2778-2882.

37. Beck, J. M., M. L. Warnock, J. L. Curtis, M. J. Sniezek, S. M. ArrajPeffer, H. B. Kaltreider, and J. E. Shellito. 1991. Inflammatory responses to Pneumocystis carinii in mice selectively depleted of helper T lymphocytes. Am. J. Respir. Cell Mol. Biol. 5:186-197. 